\section{The Profitability of New Citrus Plantings in Florida in the Era of Huanglongbing}

\author{
Ariel Singerman ${ }^{1}$ \\ Food and Resource Economics Department, Citrus Research and Education \\ Center, University of Florida, 700 Experiment Station Road, Lake Alfred, FL \\ 33850
}

\author{
Marina Burani-Arouca and Stephen H. Futch \\ Citrus Research and Education Center, University of Florida, 700 \\ Experiment Station Road, Lake Alfred, FL 33850
}

Additional index words. citrus economics, citrus greening, HLB

\begin{abstract}
The Florida citrus industry has been enduring the impact of citrus greening since 2005. The disease has been the main driver for the state's citrus production to plummet by $80 \%$ in the past 13 years, causing the industry to downsize drastically. Planting new groves is key to ensuring a supply of fruit for processors and packinghouses to stay in business. However, a key question is whether it makes economic sense to plant a new grove in the current environment. We estimate the establishment and production costs for a new grove under endemic Huanglongbing (HLB; citrus greening) conditions for three different tree planting densities under different market conditions and examine their profitability. Our results show that establishing a new grove with a tree density similar to that of the state's average is not profitable under current market conditions. However, greater tree densities are profitable despite the greater level of investment required.
\end{abstract}

The Florida citrus industry has faced multiple challenges during the past 20 years. On the supply side, such challenges have included the expansion of urban development, resulting in a decrease in agricultural land (Hernandez et al., 2012; Kautz et al., 2007); the reduction of domestic labor supply availability with its consequent increase in cost (Emerson, 2007; Wu and Guan, 2016); as well as the introduction of exotic diseases (Gottwald et al., 2002). The industry has also seen challenges on the demand side. In Florida, $\approx 90 \%$ of the citrus crop is processed for juice (U.S. Department of Agriculture, National Agricultural Statistics Service, 2018), and the introduction of new and alternative beverages available to consumers has increased the competition among beverage products during the past few years (Terazono and Hume, 2016). In addition, consumer concerns and media reports about sugar content in orange juice (Barclay, 2014; Saner, 2014; Time Magazine, 2014) have likely affected demand negatively, which triggered a response from the industry to address them (Florida Department of Citrus, 2016). Changes in consumer lifestyles and

Received for publication 20 July 2018. Accepted for publication 13 Sept. 2018.

This research was funded by the U.S. Department of Agriculture, National Institute of Food and Agriculture (NIFA), Specialty Crop Research Initiative (SCRI), and Citrus Disease Research and Extension Program (CDRE) project 2015-70016-23010.

'Corresponding author. E-mail: singerman@uff.edu. estimates are the authors' calculations. canker-affected trees in Florida, such disease became endemic across the state (Gottwald et al., 2002; Weaver, 2016). Thus, when plant pathologists recommended the eradication of HLB-affected trees as part of the disease management plan (Bové, 2006), many Florida growers were reluctant to adopt such a strategy and opted instead for keeping the trees. This was not only because of the futile efforts to try to eradicate canker, but also because fruit prices were high at the time. Therefore, the opportunity cost of removing trees that were producing fruit was too high for many growers. Without inoculum removal, HLB spread rapidly across Florida. In 2015 , it was estimated that $90 \%$ of the area of a citrus operation in the state was affected by HLB (Singerman and Useche, 2017). To date, there is no cure or successful management strategy to deal with HLB. As trees become increasingly affected by the disease, they suffer premature fruit drop, the fruit harvested is smaller and misshapen, and the juice quality is compromised, all resulting in lower yield. In addition, tree mortality and cost of production also increase.

Production costs have increased significantly compared with pre-HLB levels. Figure 1 shows real cultural production costs for processed oranges in Southwest Florida. On a per-hectare basis and using 2017 as the base year, costs increased from \$2869 in 2003-04 to $\$ 4804$ in $2016-17$, up $67 \%$ during that period. Such an increase in cost was mainly a result of growers using more foliar sprays and fertilizer (Singerman and Burani-Arouca, 2017). Figure 1 also shows that, on a per-box basis, real cultural production costs have increased from $\$ 2.71$ in $2003-04$ to $\$ 10.40$ in 2016-17, which represents a $283 \%$ increase. The reason for the greater percentage increase on a per-box basis is a result of the simultaneous increase in cost per hectare and decrease

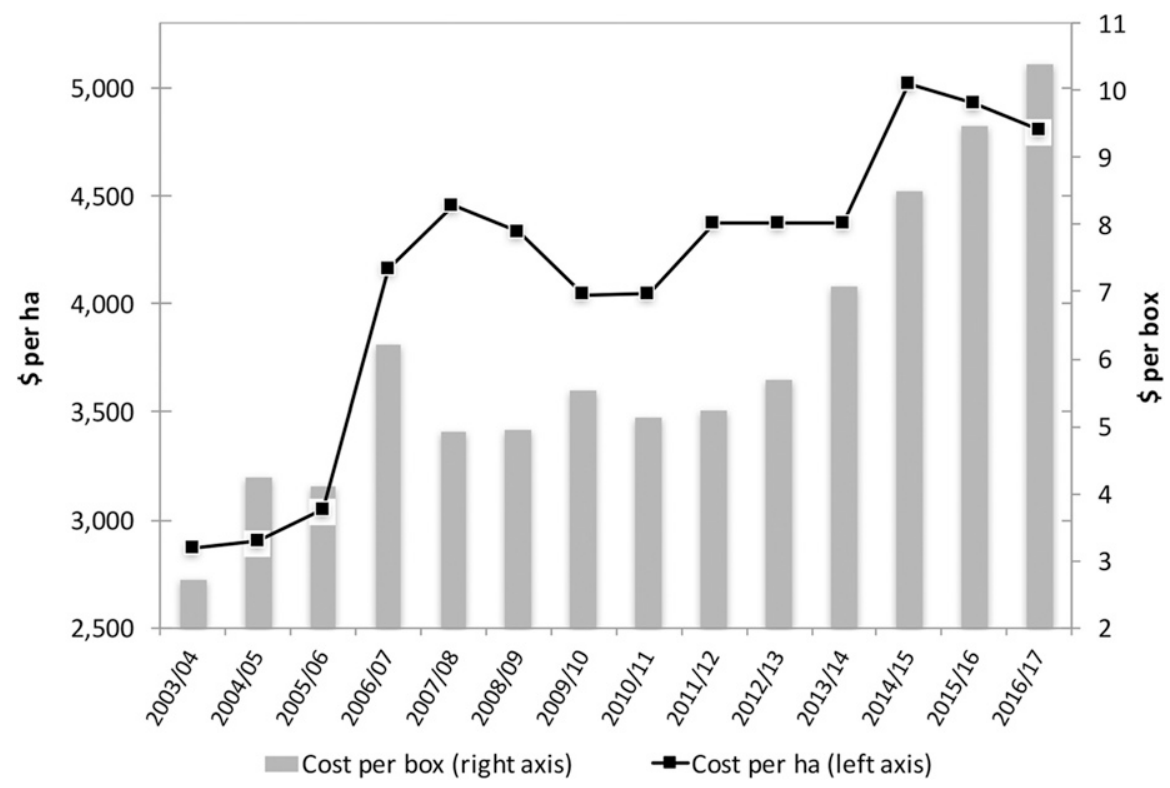

Fig. 1. Real cultural cost of production for processed oranges in Southwest Florida [Producer price index (PPI) $2017=100$ ]; $40.82 \mathrm{~kg} /$ box. Source: University of Florida, Institute of Food and Agricultural Sciences; Citrus Research and Education Center; Multiple Annual Cost of Production reports. Revenue 
in yield per hectare. During the same period, as a result of the decrease in supply (and as economic theory predicts), on-tree prices per box increased. Such an increase in real prices was by $122 \%$ (U.S. Department of Agriculture, National Agricultural Statistics Service, 2018). Thus, the greater increase in cost per box relative to price has resulted in a lack of profitability for the average grower, particularly during the past few seasons (Fig. 2).

As a consequence of the challenges the industry has been facing, but in particular as a result of the lack of profitability, it is not surprising that the rate of area lost has been larger than that of area planted (Fig. 3). And, as shown in Fig. 3, the difference between the two rates has also been increasing during the past few years. Consequently, the bearing area for oranges in Florida has decreased from 229,000 ha in 2003-04 to 149,000 ha in 2016-17 (Fig. 4). Such a decrease in area also denotes the reduction in the number of citrus growers across the state. Figure 5 shows the number of operations by farm size through time. The number of citrus growers in all four categories decreased from 7167 in 2002 to 3122 in 2012. However, the two categories with a smaller area- 0.4 to 19.9 ha and 20 to 100.9 ha-decreased by $59 \%$ and $52 \%$, respectively, whereas the decrease in the two categories of growers with a larger area were $34 \%$ and $40 \%$, respectively. Thus, the reduction in the number of growers has been greater in absolute and percentage terms for smaller operations. Operations with areas between 0.4 to 19.9 ha still represented $69 \%$ of the total number of citrus operations in Florida in 2012. However, they accounted for $\approx 6 \%$ of the citrus-bearing area. The representativeness of operations with am area greater than 303 ha increased by $4 \%$ from 2002 to 2012 . The 2017 census data will be released by U.S. Department of Agriculture, National Agricultural Statistics Service in 2019 , but given the impact of HLB, it is very reasonable to assume that such a trend has continued because, under current circumstances, it can be sensibly argued that smaller growers have had a harder time staying in business relative to larger growers.

The downsizing of the industry in recent years has not only occurred at the grower level, but also at the industry level. Figure 6 shows that the number of juice processing facilities decreased from 41 in 2003-04 to 14 in 2016-17, whereas the number of packinghouses decreased from 79 to 26 during the same period. The reduction in infrastructure is particularly troublesome. After a juice processing plant or packinghouse shuts down, the facility is put up for sale and is, therefore, unlikely to reopen. To prevent more growers and the infrastructure from going away, and to keep the Florida citrus industry afloat until a cure or management strategy for HLB is found, several public and private incentive programs for replanting have been made available to growers (Singerman, 2017; Spreen and Zansler, 2016). Such programs can incentivize growers to invest in a new citrus grove. However, and perhaps more

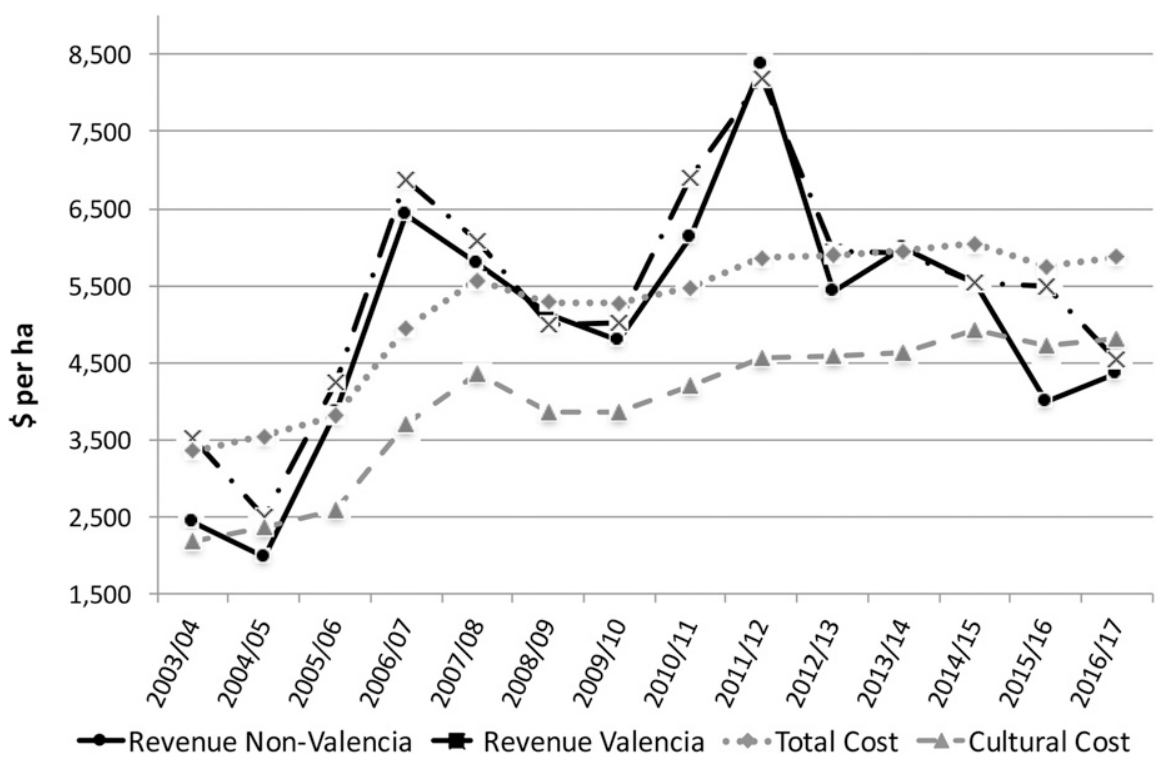

Fig. 2. Revenue and cost of production for processed oranges in Southwest Florida. Source: U.S. Department of Agriculture-Natural Agricultural Statistics Service. Revenue estimates are the authors' calculations.

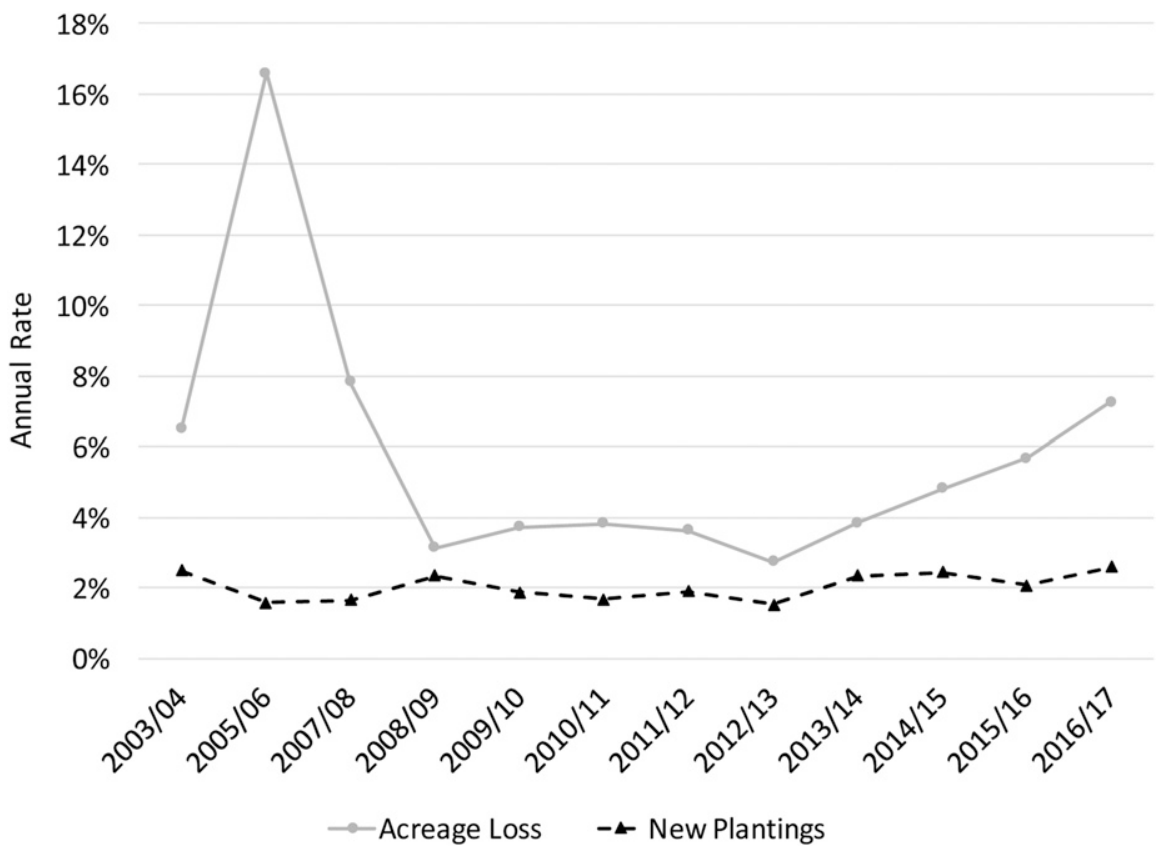

Fig. 3. Annual area loss and new plantings rates for oranges in Florida. Source: U.S. Department of Agriculture-Natural Agricultural Statistics Service, Florida Citrus Statistics. Authors' calculations.

important, a key question is whether current practices - in particular, the typical grove planting density - are still valid (i.e., profitable) in the current environment. Thus, the purpose of this study is 2-fold: first, to estimate the establishment and production costs for a new grove under endemic HLB conditions for three different tree planting densities; and second, to examine the profitability of those three different densities under different production and market conditions.

\section{Materials and Methods}

The current analysis is for 'Valencia' oranges, which is the predominant late cultivar produced in Florida and has accounted for $\approx 55 \%$ of the bearing area of oranges grown in the state during the past few years. The choice of this cultivar determines the values for yields and prices used in our model. Our cost estimates, however, are also applicable to early cultivars. The annual cost of production is based on survey data collected in Southwest Florida in 2016-17 for growing processed oranges (Singerman, 2018). Although the sample of growers may not be representative of the entire citrus grower population in Southwest Florida, the data represent 14,730 ha, which is a sizable area in that region. Thus, such data are the most updated, credible, and detailed source 


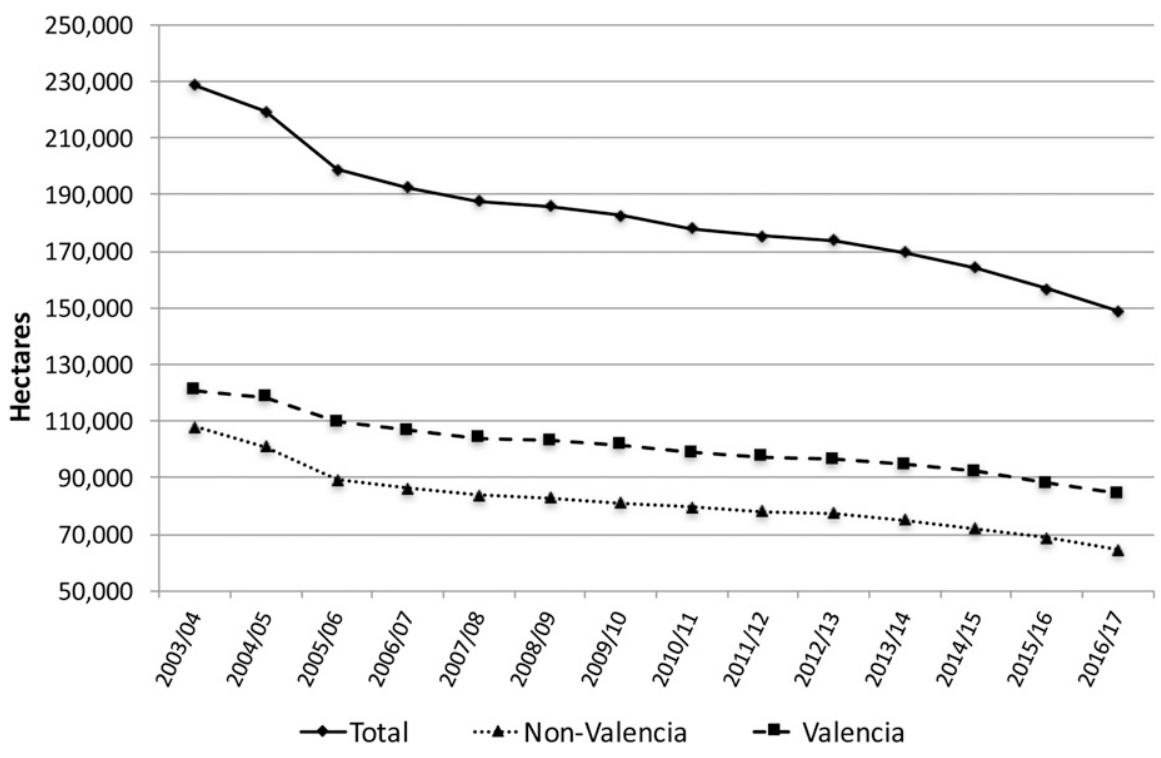

Fig. 4. Bearing area for oranges in Florida. Source: U.S. Department of Agriculture-National Agricultural Statistics Service, Florida Citrus Statistics.

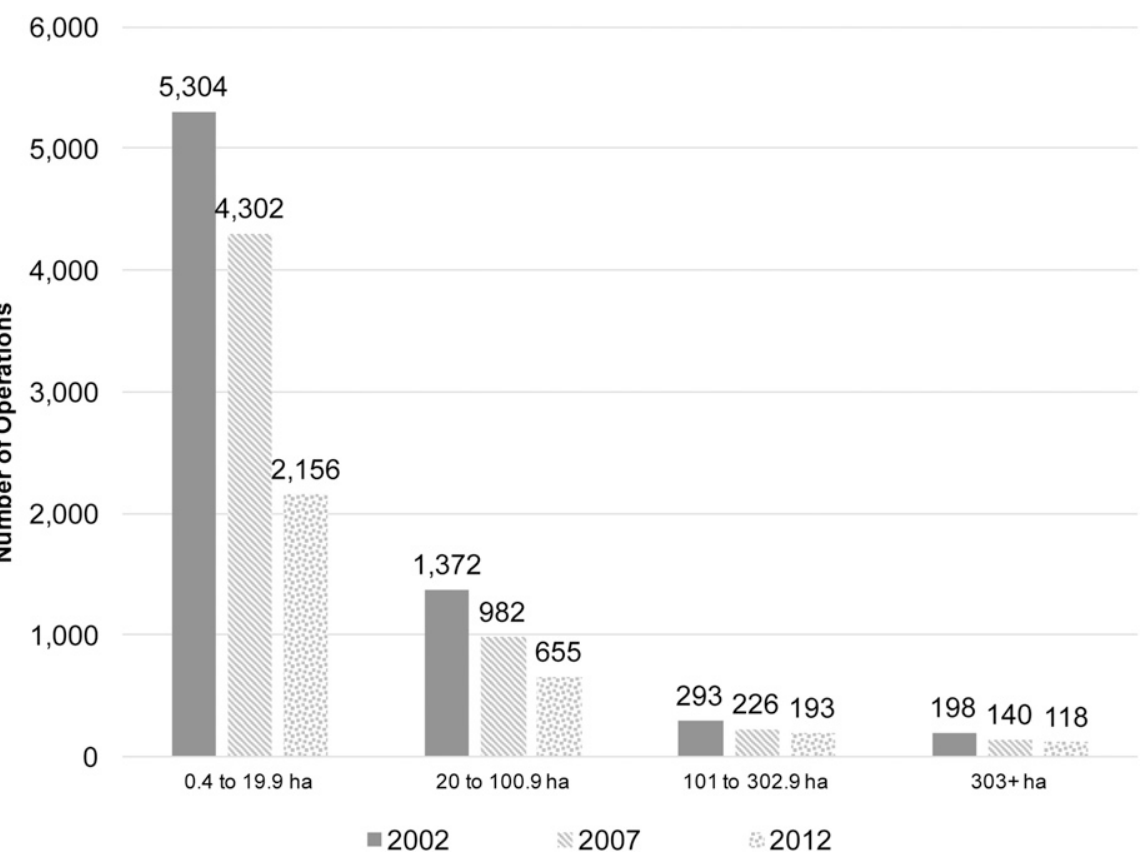

Fig. 5. Number of citrus operations in Florida by farm size (area). Source: U.S. Department of AgricultureNational Agricultural Statistics Service, Census of Agriculture data $(2002 ; 2007 ; 2012)$.

available on the cost of production of citrus in Florida in the era of HLB. The estimates include both the costs of materials and the costs associated with their application (i.e., labor). The tree density baseline for our analysis is 358 trees/ha, which is the average tree density reported by growers participating in the survey, and it is also about the state average for a citrus grove in Florida, which is 339 trees/ha (U.S. Department of Agriculture, National Agricultural Statistics Service, 2018). The between-row and in-row tree spacing associated with 358 trees/ha is $7.6 \times 3.7 \mathrm{~m}$.

In addition to the tree density baseline of 358 trees/ha, we also analyzed two greater tree densities: 544 trees/ha (with between-row and in-row tree spacing of $6.7 \times 2.7 \mathrm{~m})$ and 749 trees/ha (with between-row and in-row tree spacing of $5.5 \times 2.4 \mathrm{~m}$ ). The choice for these two greater densities is based on the feedback we obtained from growers who had already planted greater density groves.

To estimate the necessary investment in irrigation and frost protection, the first step was to determine the quantity of water needed for each tree density. Parsons and Morgan (2017) reported the per-tree water needs for a grove with 346 trees/ha to be 53 and $148 \mathrm{~L} \cdot \mathrm{d}^{-1}$ for the winter and summer months, respectively. They also reported the per-tree water needs for a grove planted at 539 trees/ha to be 34 and $95 \mathrm{~L} \cdot \mathrm{d}^{-1}$ for the winter and summer, respectively. For computing the water required to irrigate a grove with 749 trees/ha, we extrapolated the water requirements based on the percentage of additional trees relative to 544 trees $/ \mathrm{ha}$, taking into account a reduction in per-tree water needs. To establish the volume of annual irrigation needed, we took into account the amount of water trees receive from rainfall. Thus, we estimated the historical average rainfall in three representative citrus-growing cities in Florida (Clewiston, Frostproof, and Immokalee) from 2010 to 2016 using data from the Florida Automated Weather Network. Then, based on the liters of water needed per day per tree for each tree density, we calculated the average amount of irrigated water needed each month to supplement rainfall.

To account for frost protection, we assumed four radiation frost events per year based on the work of Jackson et al. (2015). During each freeze event, the irrigation system was assumed to be run continuously for $12 \mathrm{~h}$, resulting in $48 \mathrm{~h} /$ year in which the irrigation system would pump water for freeze protection. We assumed a 20-ha irrigation zone based on feedback from irrigation supply companies. We also assumed which type of microsprinkler would be used for each tree, which in turn affected the decision of the capacity of the water well and pump needed. Note that the choice of microsprinkler, water well, and pump is different for each tree density; we gathered appropriate quotes for the equipment that would meet the requirements of each tree density. We then computed the variable costs associated with the irrigation system, such as pumping hours, diesel consumption, repairs, and maintenance, using feedback from suppliers.

We assume that the average expected lifespan of a grove in Florida has decreased from 30 to 20 years as a consequence of the impact of HLB. The disease has also affected tree mortality, which we assume to be $3 \%$ in years 2 through 6 and 5\% from years 7 through 20; these figures are based on growers' feedback. However, the tree replacement strategy for removed trees is based on a sensitivity analysis that maximizes profit. In our model, we also assume that the following cultural activities are contracted: land preparation and bedding, fertilization, hedging and topping, tree removal, and tree replacement. Regarding the land, we assume it is already owned.

Foliar sprays are the largest expense among the caretaking practices of the groves, accounting for $34 \%$ of the cultural cost of production (Singerman, 2018). Because we assume the use of tree sensing technology for the application of foliar sprays, we wanted to obtain the cost of materials on a per-tree basis by tree age. To calculate such cost per tree, we divided the cost per hectare of the foliar sprays program by the total number of trees in the year in which trees reach maturity. Taking into account the HLB stunting effect on citrus trees (HLB-affected trees do not grow as much as trees without HLB), we 


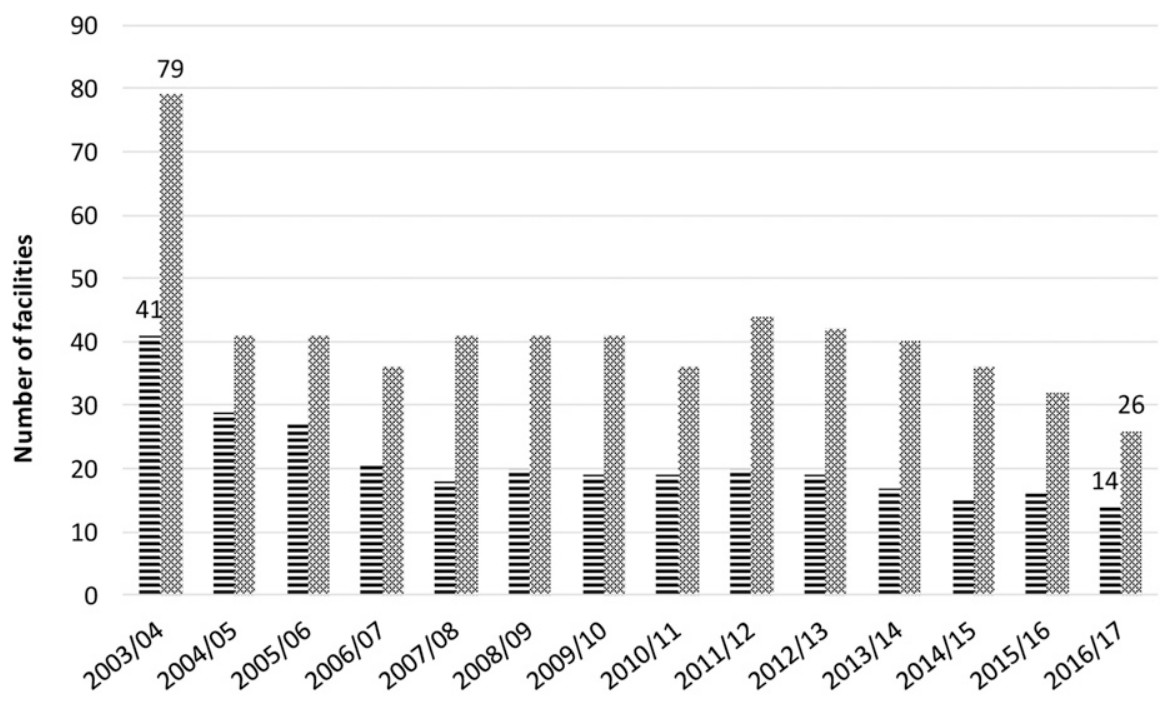

三 Juice Processing Facilities Fresh Fruit Packing Companies

Fig. 6. Number of juice processing facilities and packinghouses in Florida. Source: Florida Department of Agriculture and Consumer Services (FDACS).

assumed it would take 12 years for them to reach full size (height). Thus, the material application rate for trees between 1 and 11 years old was computed by taking into account a percentage reduction relative to mature trees based on their age (and height). After we obtained the cost on a per-tree basis by age, we computed the foliar sprays costs per hectare for each year simply by multiplying the number of trees in each cohort by the associated foliar spray cost per tree.

Fertilizer is the second-largest expense in the caretaking of the groves, which accounted for $21 \%$ of the cultural cost of production in 2016-17 (Singerman, 2018). For computing the cost of the annual fertilizer programsimilarly for foliar sprays - we also wanted to obtain fertilization rates on a per-tree basis. To calculate such rates per tree, we divided the cost per hectare of the program by the total number of trees that are 4 years old and older in year 12. Mature trees receive $100 \%$ of the rate associated with the survey cost data. To compute the cost of fertilizing younger trees, we did the following. For trees that are 1, 2, and 3 years old, we based fertilizer applications on University of Florida, Institute of Food and Agricultural Sciences recommendations (Morgan et al., 2017), which specify using three dry fertilizer applications and eight liquid fertilizer applications per year. For trees that are between 4 and 11 years old, we computed a reduction in their material application rate relative to a mature tree based on their height.

To compute the cost of the fertilizing program for tree densities of 544 and 749 trees/ha, we calculated the cost per tree in a similar fashion to that described earlier. However, because fertilizer recommendations are on a per-hectare basis, we applied a cap equal to the cost of the mature trees' program in the 358-tree/ha density. Regarding the annual application cost per hectare for dry fertilizer, we included an application cost upcharge of $11 \%$ and $44 \%$ for 544 and 749 trees/ha, respectively. Such upcharges are based on the extra cost of fuel and labor involved in the applications resulting from the additional number of rows per hectare in greater density groves relative to the 358 tree/ha density.

A summary of the annual variable costs throughout the grove lifetime is presented in Table 1 for each of the three tree densities analyzed.

Sensitivity analysis. To allow for the possibility of different types of growers planting a new grove, we also made assumptions regarding the level of investment needed in terms of machinery and irrigation. Such investment could be either full or partial to represent the cases of a new grower and that of a current grower, respectively. The difference between the scenarios is that, in the full-investment scenario, the grower needs to purchase all machinery and irrigation equipment required to manage the grove whereas, in the partial scenario, the grower only needs to make some investment in irrigation (the well and pumping station are assumed to be in place). However, in both scenarios we assume the grower needs to purchase a new tractor, ATV, and pickup truck in year 11. The rest of the machinery is assumed to be used beyond its accounting lifespan of 10 years.

Yield is a key parameter in the model, and we assume two possible scenarios for modeling it. In both scenarios, trees start to fruit 26 months after planting. In the first scenario, which we refer to as low, we assume that the boxes per tree for each of the different age cohorts are given by the U.S. Department of Agriculture, National Agricultural Statistics Service average for Southwest Florida during seasons 2013-14 through 2015-16. Their estimates represent about a $40 \%$ yield reduction compared with pre-HLB yield levels. Such a figure is in agreement with the average loss reported by growers (Singerman and Useche, 2017). In the second scenario, which we refer to as high, we assume trees yield more boxes relative to scenario 1 based on the feedback from growers with whom we visited, who attain yields greater than the state's average. Regarding quality yield, we assume that in both scenarios each box yields 6.24 pound solids (ps) (Florida Department of Citrus, 2017b).

Price is another key parameter in the model. The average delivered-in price for 'Valencia' oranges in 2016-17 was $\$ 2.85 /$ ps (Florida Department of Citrus, 2017a). To obtain the on-tree price (which is the price the grower receives, and the basis we use to compute profitability) from the delivered-in price, we subtract $\$ 3.27 /$ box (Singerman et al., 2017) for harvesting and $\$ 0.07 /$ box for Florida Department of Citrus assessment from delivered-in prices and obtain $\$ 2.31 / \mathrm{ps}$. We model three scenarios to represent possible market conditions: low, medium, and high prices. Thus, we use the on-tree price estimate as the medium-price scenario, and assume a $15 \%$ decrease (10\% increase) with respect to such price to establish the low (high) scenario of $\$ 1.97 / \mathrm{ps}(\$ 2.55 / \mathrm{ps})$. These values translate to delivered-in estimates of $\$ 2.50 / \mathrm{ps}$ and $\$ 3.08 / \mathrm{ps}$, respectively. These prices were chosen to represent a range of conservative current and future potential market conditions. We assume that fruit prices and input costs are constant throughout the investment period, which, in the case of the former, assumes away weather shocks derived from potential freezes and/or hurricanes. To the extent that prices and yield are a natural hedge, and taking into account that the main purpose of this analysis is to illustrate the profitability of different planting densities, we consider this assumption to be reasonable. We also assume the annual cash flows are expressed in real terms, so we do not need to adjust them for inflation. Thus, the resulting rate of return is in real terms as well.

\section{Results}

For each tree density, we computed the set of different scenarios described in the previous section by combining the investment requirement (full or partial), cost of production, yields, and prices to obtain the returns. We then compiled an annual financial budget, which is the basis for the investment analysis - the typical methodology for establishing the profitability of a long-term investment.

Figure 7 shows the cash expenses for each of the three tree densities throughout the 20year investment period. Figure 7A denotes the expenses for the partial-investment scenario and Figure 7B shows the full-investment scenario. In the partial investment, expenses in year 1 are $\$ 17,071, \$ 20,395$, and $\$ 25,366 / \mathrm{ha}$ in year 1 for 358,544 , and 749 trees/ha, respectively. The latter two are $19 \%$ and $49 \%$ greater relative to the 358 -trees/ha baseline. In years 2 and 3, expenses for the 544- and 749trees/ha densities decrease, but are still $\approx 20 \%$ 


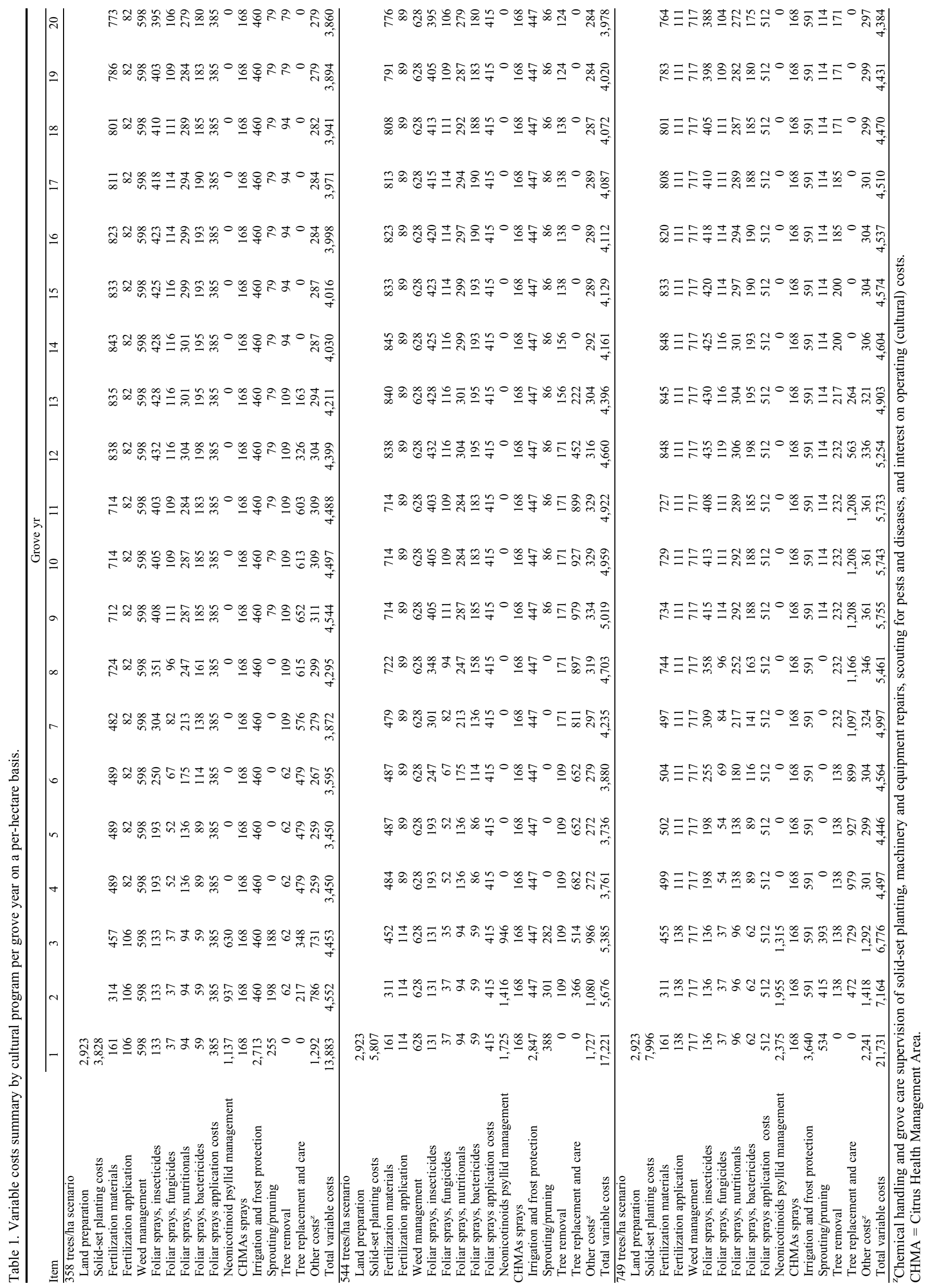


A.

35,000

30,000

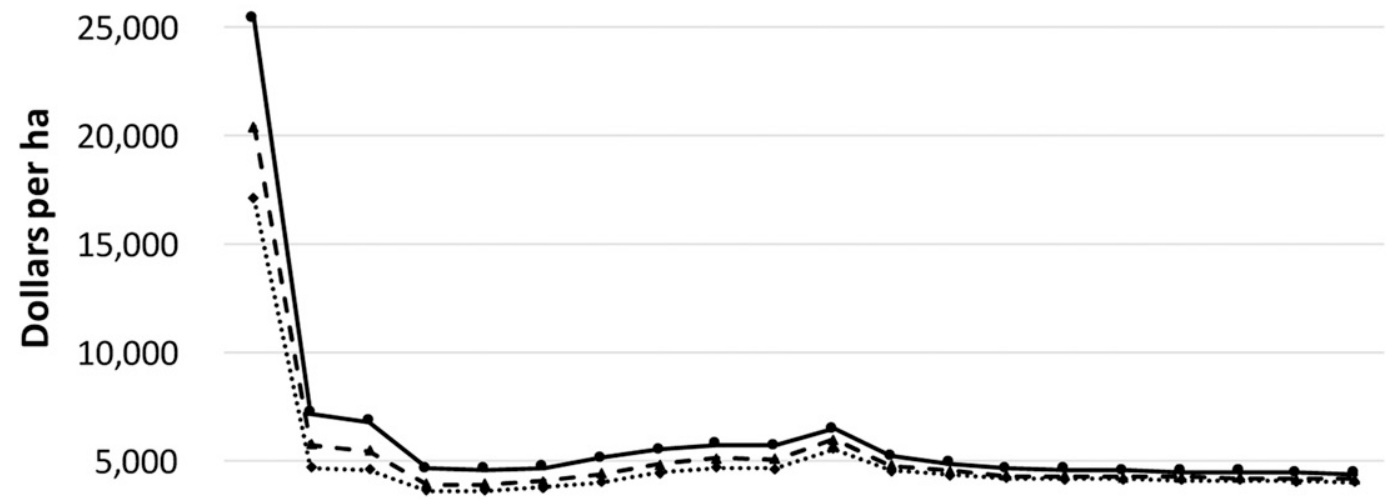

$\begin{array}{llllllllllllllllllll}1 & 2 & 3 & 4 & 5 & 6 & 7 & 8 & 9 & 10 & 11 & 12 & 13 & 14 & 15 & 16 & 17 & 18 & 19 & 20\end{array}$

Grove Year

……358 TPH $\quad$ - $544 \mathrm{TPH} \rightarrow 749 \mathrm{TPH}$

B.

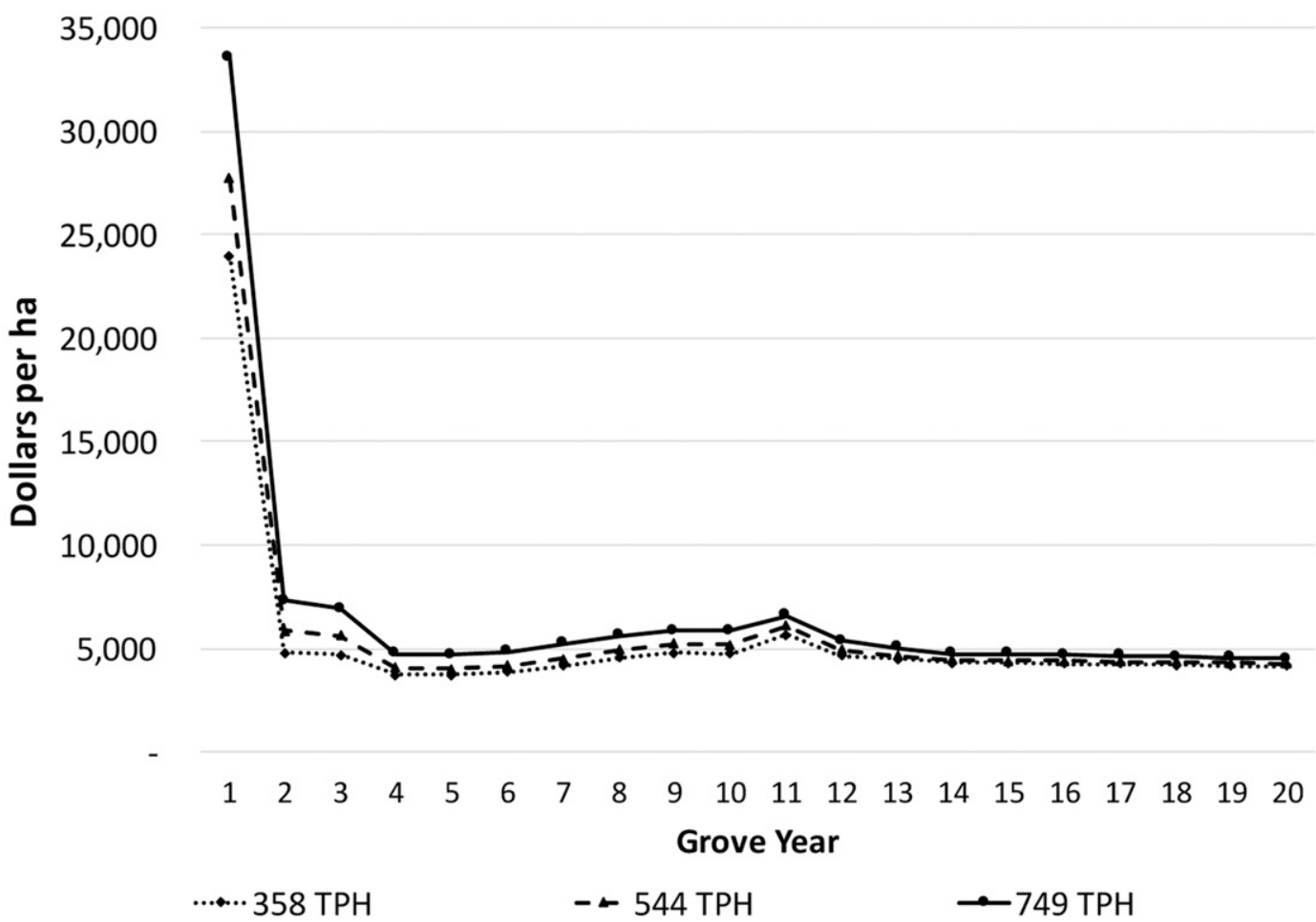

Fig. 7. Cash expenses by grove year for 358, 544, and 749 trees/ha (TPH). (A) Partial investment scenario: All machinery but only some irrigation equipment need to be purchased. The well and pumping station are assumed to be in place. (B) Full investment scenario: All machinery and irrigation equipment need to be purchased.

and $50 \%$ greater with respect to those of a grove planted at 358 trees/ha. However, in years 4 through 11 , expenses are about between $7 \%$ to $10 \%$ greater for the 544 -trees/ha density, and $16 \%$ to $28 \%$ greater for the 749-trees/ha density compared with the base- line density. Starting in year 12, expenses are up to $6 \%$ and $15 \%$ greater for the 544 - and 749 trees/ha density, respectively, compared with the 358-trees/ha density baseline. As shown in Fig. 7B, results for the full-investment scenario are similar. As Fig. 7 and the comparisons here illustrate, annual expenses for greater tree densities do not increase proportionally with the number of trees planted.

Figure 8 shows yield per hectare by grove year for each of the three tree densities. It can be seen from the figure that for tree densities 
of 544 and 749 trees/ha, yield per hectare does increase proportionally to the greater number of trees planted relative to the 358 tree/ha density baseline. Such proportional increase is imposed by assumption because, as described earlier, we use data on yield per tree from the U.S. Department of Agriculture,
National Agricultural Statistics Service (2018) for our calculations. However, starting in year 10, the proportional change decreases slightly as a result of the effect of the penalty we impose for canopy closure and resetting strategy for the greater densities. The assumptions on yield we made are feasible under current conditions. Note, for example, the maximum yield of 922 boxes/ha is achieved in year 9 for the 749-trees/ha density. As a reference, the average yield per hectare for 'Valencia' oranges in Florida in 2003-04 was 961 boxes/ha with an average tree density of 329 trees/ha.

A.

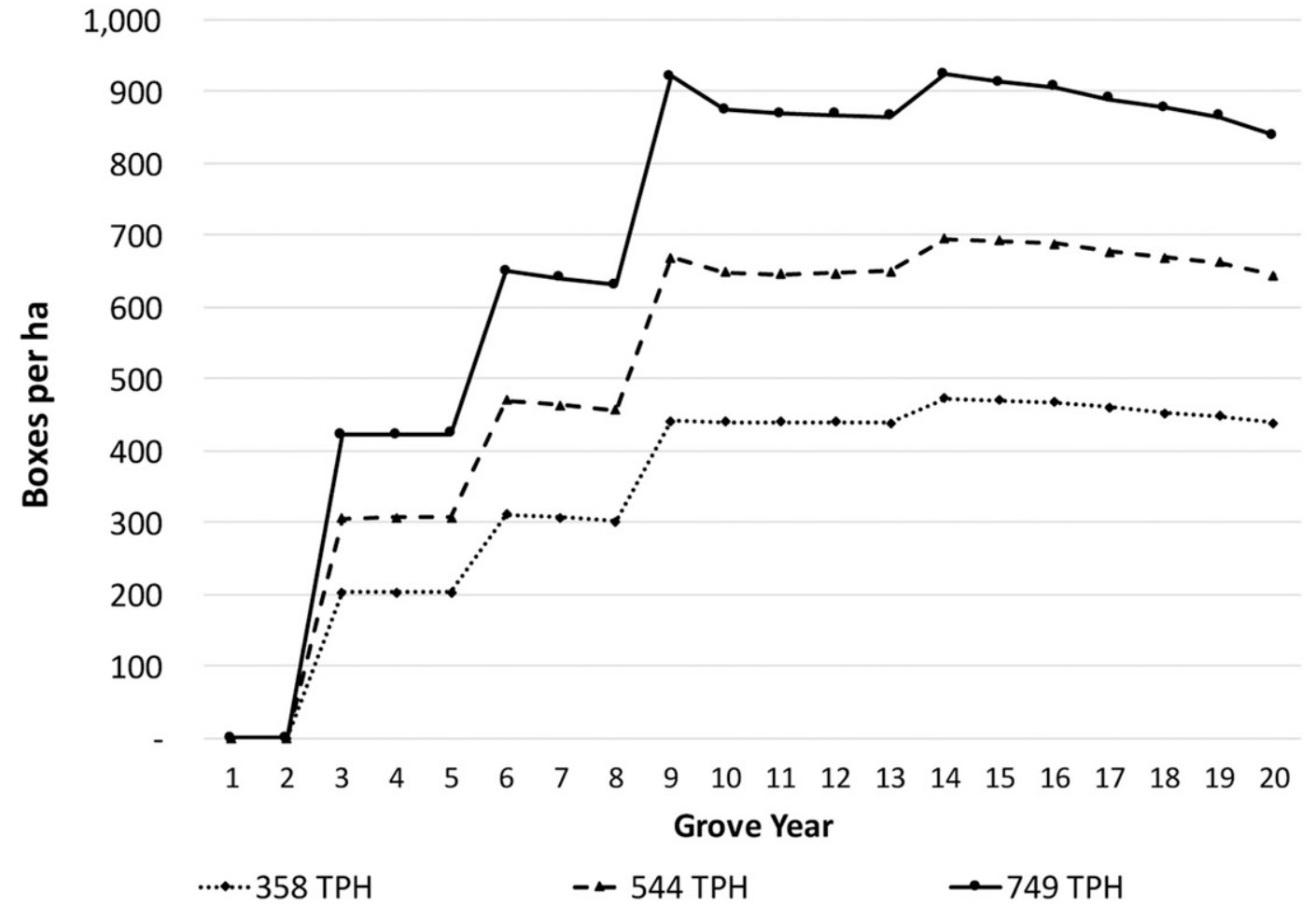

B.

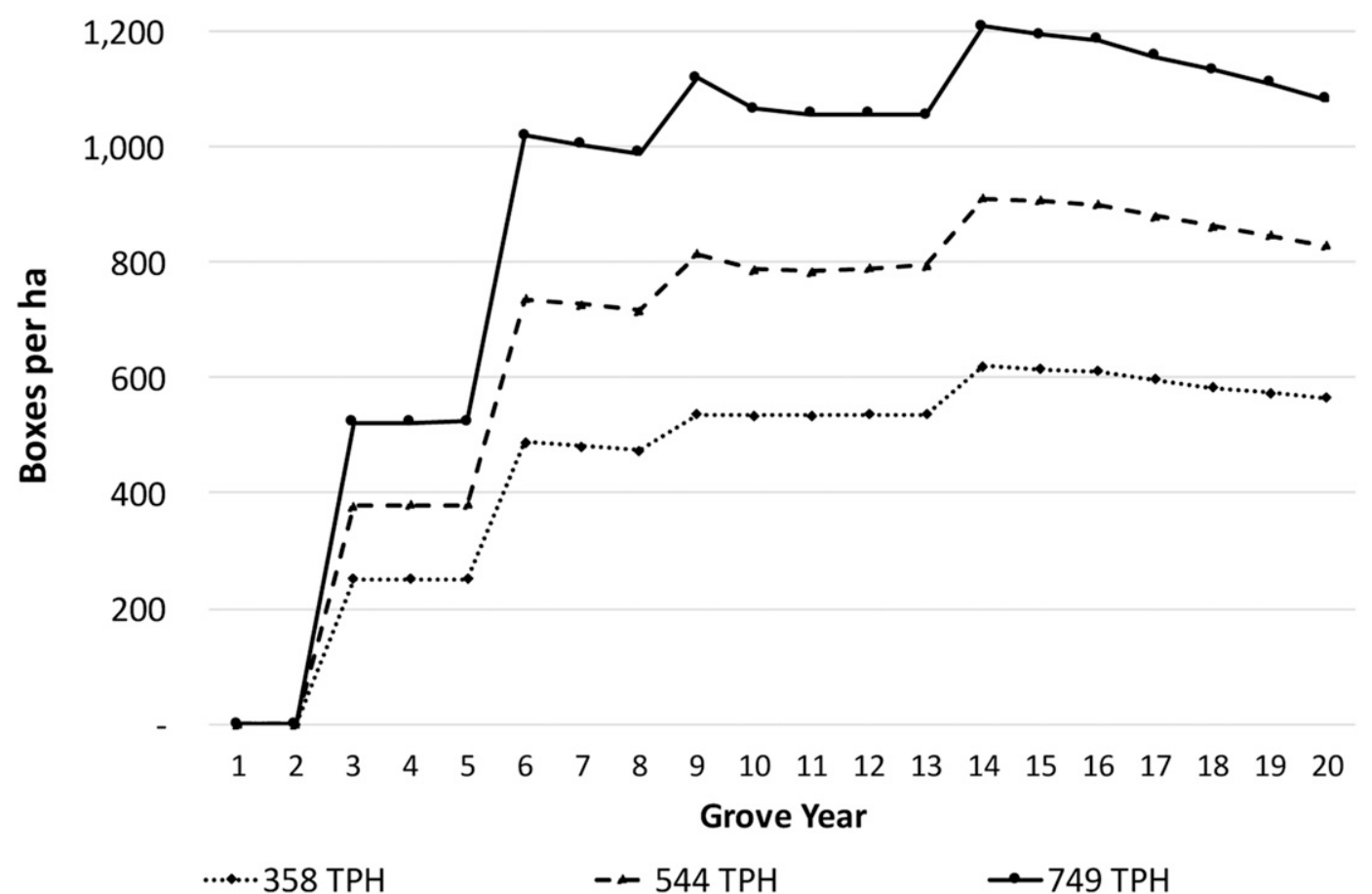

Fig. 8. Yield per hectare by grove year for 358, 544, and 749 trees/ha (TPH). (A) Low-yield scenario: Boxes per hectare are based on data from the U.S. Department of Agriculture-Natural Agricultural Statistics Service on boxes per tree for each of the different tree age cohorts in Southwest Florida during seasons 2013-14 through 2015-16. (B) High-yield scenario: Boxes per hectare are based on data from growers. 
Investment analysis is used to evaluate the profitability of long-term investments such as an orange grove. The net present value (NPV) can be used as a methodology for such evaluation, which consists of summing all the discounted cash flows, as denoted by the equation

$$
\mathrm{NPV}=\sum_{n=1}^{N} \frac{\mathrm{CF}_{n}}{(1+r)^{n}}
$$

where $\mathrm{CF}$ is the cash flow at time $n$, and $r$ denotes the discount rate. The choice of the discount rate is key and it represents the cost of capital (or its opportunity cost). As a rule of thumb, investments with a positive NPV should be accepted and those with a negative NPV, rejected. The reasoning for accepting investments with positive NPVs is that they yield greater returns than the discount rate (i.e., cost of capital). However, it is impossible to estimate a discount rate that represents the cost of capital for all growers as each individual grower has a different opportunity cost of capital. Therefore, we show the results of the investment analysis using the internal rate of return (IRR) methodology. The IRR is the actual rate of return on the investment. As such, it depends only on the cash flows of the investment (Ross et al., 2005); it is the discount rate that makes the NPV be zero in the previous equation.

Table 2 shows the investment analysis results for the different scenarios and tree densities. Table 2 shows that in a grove with 358 trees/ha, under a scenario with low yield and low prices, the investment is not profitable; with medium prices, the partial-investment scenario yields only a $1 \%$ return. These scenarios illustrate the situation currently faced by many growers (denoted in Fig. 2). Table 2 also shows that when prices are high, there is a modest return between $1 \%$ and $3 \%$, depending on the

Table 2. Internal rate of return (IRR) from investing in a new citrus grove.

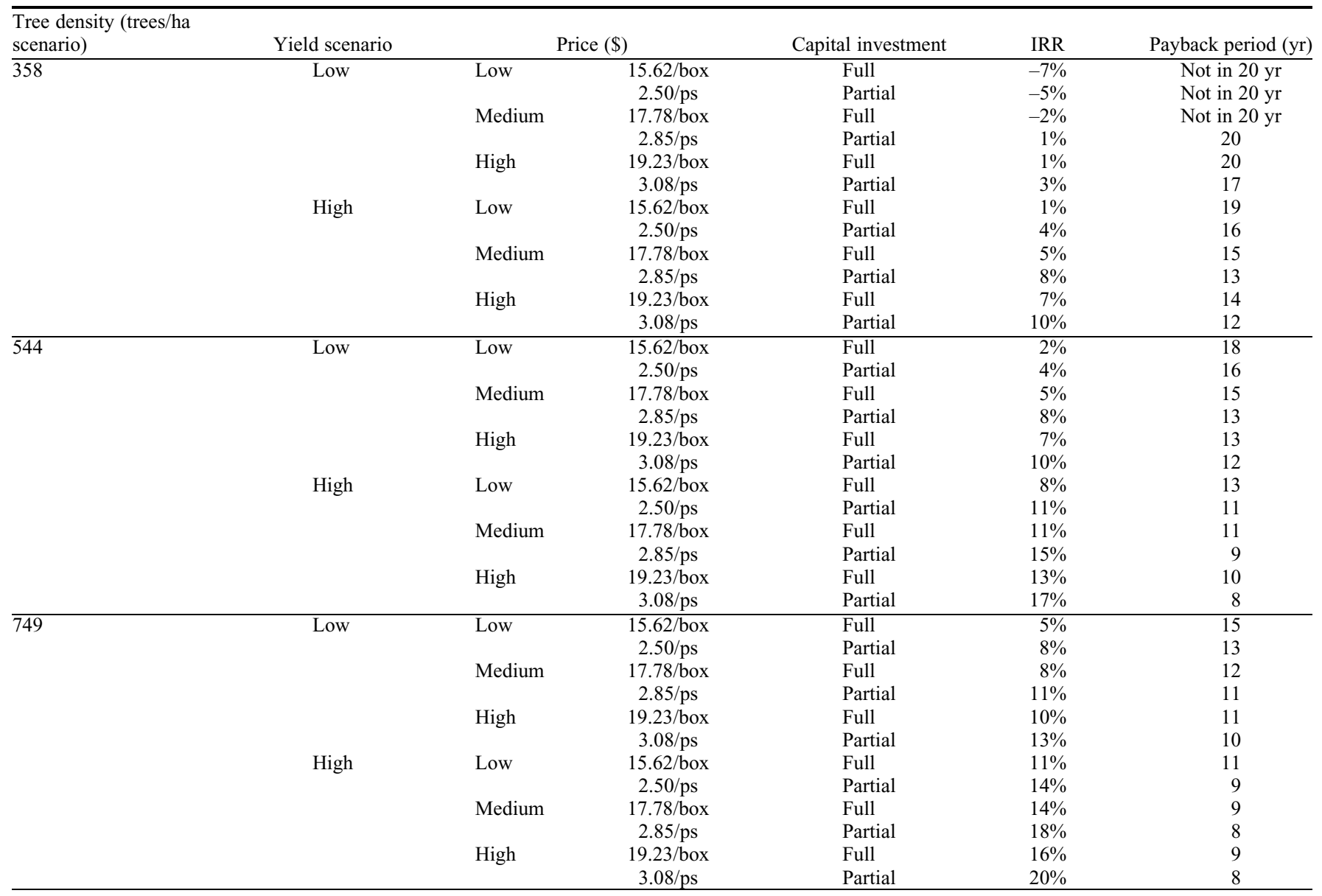

ps = pound solids.

Table 3. Breakeven prices for different payback periods

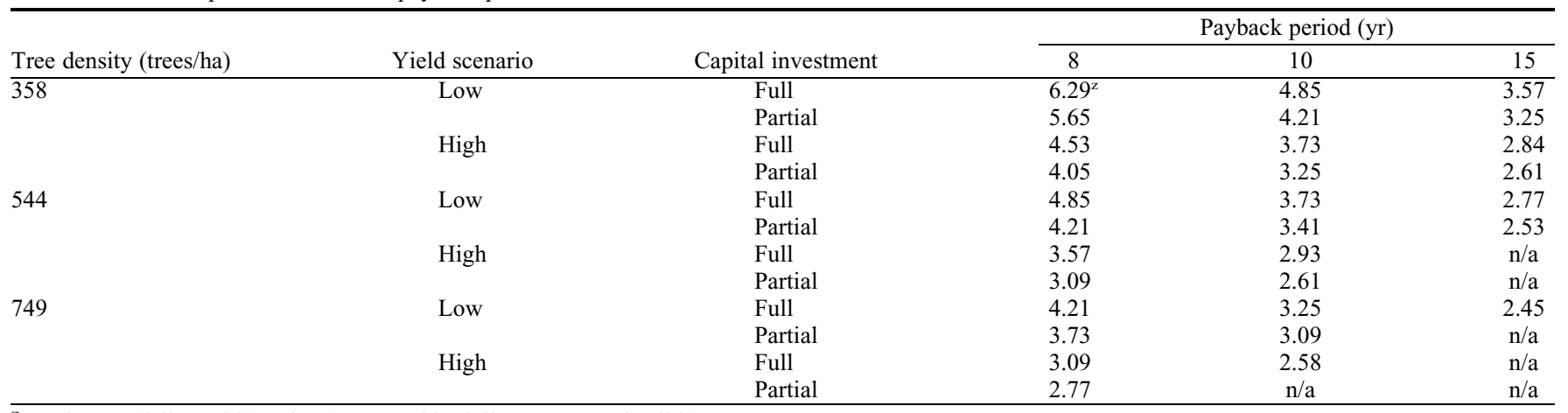

${ }^{\mathrm{z}}$ Breakeven (delivered-in) price (measured in dollars per pound solids).

$\mathrm{n} / \mathrm{a}=$ the payback period under that scenario is attained sooner. 
level of investment in machinery and irrigation. Under a high-yield scenario, the return of a grove with 358 trees/ha varies from $1 \%$ up to $10 \%$, depending on the combination of prices and investment requirement. The payback period is 12 years in the best-case scenario.

Table 2 also shows that in a grove with 544 trees/ha, despite the greater initial investment relative to the 358-trees/ha density baseline, the returns are positive. Under a low-yield scenario, the rate of return ranges between $2 \%$ and $10 \%$, depending on market conditions and the level of investment required. The payback period is at least 12 years. Under a high-yield scenario, depending on the level of prices and investment, the rate of return ranges from $8 \%$ to $17 \%$, and the payback period can be as short as 8 years in the best-case scenario.

Last, Table 2 shows the returns for a grove with 749 trees/ha improved those obtained for 544 trees/ha even further (despite the even greater level of initial investment relative to the baseline). Under a low-yield scenario, the rate of return ranges between $5 \%$ and $13 \%$, depending on market conditions and the level of investment needed. In a high-yield scenario, depending on prices and the investment required, the return ranges from $11 \%$ to $20 \%$, and the payback period can be as short as 8 years in some cases. Table 3 provides a summary of breakeven prices in each scenario for different payback periods - namely, 8,10 , and 15 years.

\section{Conclusions}

We analyzed the investment of planting a new grove in Florida under the current endemic HLB environment across the state. We found that establishing a new grove with a tree density similar to that of the state's average is not profitable under current market conditions. Such a density only attains a modest return under potential greater prices. Despite the greater level of investment required for planting 544 and 749 trees/ha, such investments are profitable under the assumptions and scenarios we analyzed.

The main driver for the results discussed here is that, although the costs of greater density groves do not increase proportionally with the number of trees, yield per hectare does. More specifically, although with greater density groves each tree produces somewhat less yield on a per-tree basis relative to a lower density grove, the greater number of trees contributes to obtaining a greater yield per hectare. Therefore, planting greater density groves could help partially offset the impact of HLB by generating a simultaneous increase in yield per hectare and a decrease in the cost of production per box (as a result of costs being allocated to a greater number of boxes), ultimately resulting in an increase in profitability per hectare.

Our results should prove useful not only to citrus growers to help in their decision-making process of determining whether to plant a high-density grove, but also to other industry stakeholders and policymakers in their efforts to support the Florida citrus industry in dealing with HLB. A policy implication that follows from our findings is that public and private incentive programs for replanting should encourage growers' investment in greater density groves, and should take into account the significantly greater expenses related to such an investment.

The limitations of this analysis are the following. First, because HLB was first found in Florida in 2005, it is not yet clear how trees will be affected by the disease in the future. Therefore, in our model, the impact of HLB on yield of trees that are 13 years old and older is a projection based on current data. Second, we did not include any potential impact of weather events such as freezes or hurricanes (and their effect on prices) in this analysis. Third, potential future management strategies or solutions to HLB could involve planting (new) trees with resistant or tolerant traits to the disease, which could potentially make an existing grove with trees that do not have such traits obsolete.

\section{Literature Cited}

Barclay, E. 2014. Fruit juice vs. soda? Both beverages pack in sugar, health risks. National Public Radio. <https://www.npr.org/sections/thesalt/2014/ 06/09/319230765/fruit-juice-vs-soda-both-beveragespack-in-sugar-and-health-risk $>$.

Bové, J.M. 2006. Huanglongbing: A restructive, newly-emerging, century-old disease of citrus. J. Plant Pathol. 88(1):7-37.

Emerson, R.D. 2007. Agricultural labor markets and immigration. Choices 22(1):57-66.

Florida Department of Citrus. 2016. 100\% OJ and sugar. $<\mathrm{https}: / / \mathrm{www}$.floridacitrus.org/newsroom/ news/faqs-100-oj-and-sugar/>.

Florida Department of Citrus. 2017a. Post estimate fruit price report 06.03.17. <https://app.box. com/embed/s/4905ob93hh/file/189137867228? showItemFeedActions=true\&showParentPath=true $>$.

Florida Department of Citrus. 2017b. Processor report July 17, 2017a. <https://app.box.com/ embed/s/byddpj 7ys2/file/202615269604? showItemFeedActions=true\&showParentPath=true $>$.

Gottwald, T.R., J.H. Graham, and T.S. Schubert. 2002. Citrus canker: The pathogen and its impact. Plant Health Prog. doi: 10.1094/PHP2002-0812-01-RV (online).

Heng, Y., L.A. House, and H. Kim. 2018. The competition of beverage products in current market: A composite demand analysis. Agr. Resources. Econ. Rev. 47(1):118-131.

Hernandez, J.L., S. Hwang, F. Escobedo, A. Davis, and J. Jones. 2012. Land use change in central Florida and sensitivity analysis based on agricultural to urban extreme conversion. Weather Clim. Soc. 4(3):200-211.

Jackson, J.L., K. Morgan, and W. R. Lusher. 2015 Citrus cold weather protection and irrigation scheduling tools using Florida Automated Weather Network (FAWN) data. University of Florida, Institute of Food and Agricultural Sciences (IFAS), Electronic Data Information Source (EDIS) document SL 296.

Kautz, R., B. Stys, and R. Kawula. 2007. Florida vegetation 2003 and land use change between 1985-89 and 2003. Fla. Sci. 70(1):12-23.

Morgan, K.T., D.M. Kadyampakeni, M. Zekri, A.W. Schumann, T. Vashisth, and T.A. Obreza.
2017. Nutrition management for citrus trees. 2017-2018 Florida citrus production guide. UF/IFAS Extension, University of Florida. $<\mathrm{http} / / / \mathrm{www} . c r e c . i f a s . u f l . e d u /$ extension/pest/ PDF/2017/Nutrition_Mangement.pdf>.

Parsons, L.R. and K.T. Morgan. 2017. Management of microsprinkler systems for Florida citrus. University of Florida, Institute of Food and Agricultural Sciences (IFAS), Electronic Data Information Source (EDIS) document HS 958. <http://edis. ifas.ufl.edu/pdffiles/HS/HS20400.pdf > .

Ross, S.A., R.W. Westerfield, and J. Jaffe. 2005. Corporate finance. McGraw-Hill, New York, NY.

Saner, E. 2014. How fruit juice went from health food to junk food. The Guardian. <https:// www.theguardian.com/lifeandstyle/2014/jan/ 17/how-fruit-juice-health-food-junk-food $>$.

Singerman, A. 2017. Summary of three incentive programs available to Florida citrus growers. $<$ http://www.crec.ifas.ufl.edu/extension/economics/ pdf/Summary_of_incentive_programs.pdf $\$$.

Singerman, A. 2018. Cost of production for processed oranges in southwest Florida, 2016/17. University of Florida, Institute of Food and Agricultural Sciences (IFAS), Electronic Data Information Source (EDIS) document FE 1038. $<$ http://edis.ifas.ufl.edu/pdffiles/FE/FE103800. pdf $>$.

Singerman, A. and M. Burani-Arouca. 2017. Evolution of citrus disease management programs and their economic implications: The case of Florida's citrus industry. University of Florida, Institute of Food and Agricultural Sciences (IFAS), Electronic Data Information Source (EDIS) document FE 915. <http://edis.ifas.ufl. edu/fe915>.

Singerman, A., M. Burani-Arouca, S.H. Futch, and R Ranieri. 2017. Harvesting charges for Florida citrus, 2016/17. University of Florida, Institute of Food and Agricultural Sciences (IFAS). <http://www. crec.ifas.ufl.edu/extension/economics/pdf $/ 2017 \%$ 20Harvesting\%20Costs\%2020170906.pdf×

Singerman, A. and P. Useche. 2017. Florida citrus growers' first impressions on genetically modified trees. AgBioForum 20(1):6783.

Spreen, T.H. and M.L. Zansler. 2016. Economic analysis of incentives to plant citrus trees in Florida. HortTechnology 26(6):720-726.

Terazono, E. and N. Hume. 2016. Are the sweet days over for orange juice? Financial Times. $<$ https://www.ft.com/content/c4bc7f92-079111e6-9b51-0fb5e65703ce>.

Time Magazine. 2014. 5 Juices with more sugar than soda. <http://time.com/103898/5-juices-with-moresugar-than-soda/>

U.S. Department of Agriculture (USDA). 2002; 2007; 2012. Census of Agriculture. U.S. Department of Agriculture, National Agricultural Statistics Service, Washington, DC.

U.S. Department of Agriculture, National Agricultural Statistics Service. 2018. Florida Citrus Statistics 2016-2017. U.S. Department of Agriculture, National Agricultural Statistics Service, Washington, DC.

Weaver, J. 2016. 16 Years later, citrus canker legal battle finally goes to trial in Miami-Dade. Miami Herald. <http://www.miamiherald.com/news/ local/article 76614477.html>.

Wu, F. and Z. Guan. 2016. Foreign guest workers or domestic workers? Farm labor decisions and implications. Presented at the 2016 Agricultural \& Applied Economics Association annual meeting, 31 July 2016, Boston, MA. 